\title{
A Multidimensional CRM Approach for Enhancing Marketing Innovation Capabilities of Construction Companies Using Structural Equation Modeling
}

\author{
Prof. Dr. Tarek Taha Ahmed \\ Dean of the Faculty, Pharos University in Alexandria, Egypt
}

\begin{abstract}
Despite, customer relationship management (CRM) has reengineered the traditional marketing practices and recently gained wide attention in business and literature as an essential approach for achieving competitive advantage and profitability few works empirically investigated the impact of implementing CRM on marketing innovation capabilities in construction industry and particularly in developing countries context. In responding to this call, the current study aimed at helping to narrow the existing research gap in the literature and contribute to the accumulated knowledge by (1) empirically examining the effects of implementing the new dimensions of customer relationships on enhancing marketing innovation capabilities. (2) assessing the mediating role of CRM readiness in the relationship between CRM implementation and marketing innovation capability; (3) developing and validating a structural equation model for predicting the construction companies' marketing innovation capabilities; and (4) determining the extent to which the new multidimensional approach of CRM is actually applied in construction industry.
\end{abstract}

A multi-stage research methodology was utilized, combining quantitative and qualitative methodologies to validate the research model and empirically test the hypothesized relationships. The research design involved a cross-sectional national sample survey for data collection during September to November 2016 ( $n=186)$. The developed questionnaire was pretested and feedback from the pre-test and the panel of experts used to revise the survey instrument. The reliability analysis was taken for each construct and the results showed that the value of Cronbach's alpha of every construct is significantly higher than the reliability acceptable level (ranging from 0.81 to 0.94). Also exploratory factor analysis was used to evaluate the construct validity and the results demonstrate acceptable standard. The evidence of a good fit, reliability and validity indicated that the measurement model deemed appropriate for testing the structural model that demonstrated highly explanatory power.

The results indicated that strengthen the completeness of CRM new dimensions can establish lifetime value based on sustainable relationship and in turn enhance construction company competitive advantage and marketing innovation capability. As the current research offered a multidimensional approach of CRM differs than the traditional perspective of CRM, the results can help practitioners and construction companies to develop more customized CRM practices as well as overcoming the barriers of both organizational and technical CRM readiness. Unlike previous studies with similar objectives, this study taken a further significant step in contributing to both theory and practice and expand the research scope through integrating the most critical antecedent predictors, into one framework subject to examination for validation and relationship. Therefore, the structural research model contained variables that have not been examined simultaneously.

Keywords: Competitive advantage; CRM readiness, Customer Relationship Management (CRM); Marketing Innovation Capability, Structural Equation Modeling

\section{INTRODUCTION}

In our contemporary business environment, which characterized by highly unpredictable markets and increasing competitiveness, business organizations strive for enhancing their innovation capabilities and maximising revenues. Customer relationship management (CRM) has experienced rapid growth and gained wide attention in business and literature as an essential strategy for achieving and maintaining competitive advantage and profitability $[1,2,3,4,5,6,7,8,9,10,11,12,13$, and 14].

Marketing orientation paradigm has changed from product-centered approach to a more customercentered approach and the market power shifted to customers. Successful organizations all over the world now implement CRM to develop customer lifetime value and differentiate themselves from 
competitors through establishing, maintaining and enhancing close and long-term relationships with customers. Which enable them to detect changes in customers' needs, predict their behavior, design the appropriate communication tools, better target profitable segments, create personalized marketing plans for each segment, identify new marketing opportunities, improve customer services and satisfaction, sustain customers retention, win back lost customers, and ultimately turning them into loyal customers [4, 9, 15 and 16$]$.

Similarly, Sheth [17] indicated that CRM changed the marketing paradigm from a transactional to a relational perspective and from a market share to share of wallet objective in marketing. This led to understanding the life time value of customers; bundling of offerings; customer profitability analysis; and strategic partnering with customers. In this context, scholars [e.g. 3] emphasized that organizations that fail to match their customers' needs and keep in track with changes in customers' preferences put their existence in danger. Therefore, every organization has to know how to enter a market and keep relationships with customers for it competitive position.

Adopting this perspective, Moreno et al. [2] considered CRM as a strategic approach for managing customer relationships to create both customer and shareholder value. On the other hand, Chang et al. [16] argued that long-term customers can bring profit to firms and always is a paradox inherent in CRM implementation. This conclusion has been supported by other authors [e.g 18], they viewed CRM as the key to profitability in an increasing dynamic market and many organizations now are implementing CRM in the hope that it will enable them to better target profitable segments and ultimately increase the organization's financial performance [9].

While such approach is theoretically addressed in literature the impact of CRM implementation on marketing innovation capability has not been extensively studied. More specifically prior studies rarely investigated how CRM can affect company's capability [18]. Thus, there is a need for research that specifically examines the impact of implementing CRM on the construction companies' marketing innovation capability as an example of industry sector in developing countries and the current paper responded to this call.

\section{Research Problem, ObJectives and Plan}

Despite, customer relationship management (CRM) has reengineered the traditional marketing practices and recently gained wide attention in business and literature as an essential approach for achieving competitive advantage and profitability few works empirically investigated the impact of implementing CRM on marketing innovation capabilities in construction industry and particularly in developing countries context [e.g. 2, 9, 12, 18, 19, and 20].

In responding to this call, the current study aimed at helping to narrow the existing research gap in the literature and contribute to the accumulated knowledge by: $(a)$ empirically examining the implementation of new dimensions of CRM in the construction industry. (b) measuring its effects on enhancing marketing innovation capabilities. $(c)$ assessing the mediating role of CRM readiness in the relationship between CRM implementation and marketing innovation capabilities. $(d)$ developing and validating a structural equation model for predicting the construction companies' marketing innovation capabilities; and $(f)$ determining the extent to which the new dimensions of CRM is actually applied in construction companies.

With these objectives in view, the current research has been organized as follows: the literature and relevant studies were reviewed and analyzed. Then a research model was proposed and hypotheses were formulated to be tested in the study. This was followed by an explanation of the procedures used to obtain empirical data, measurement, and validation processes, as well as the testing of the hypotheses stated. Finally, based on paper's findings a series of conclusions with practical and academic implications and final thoughts that emphasize the great interest in the topic under analysis were presented; and then certain limitations and future lines of research with regard to this issue were highlighted.

\section{LiteratURE REVIEW AND DEVELOPING HYPOTHESES}

Relevant literature, which provided the conceptual foundation and theoretical background for this paper, and past research were extensively reviewed in order to develop more effectively the study hypotheses and the proposed model. Through this process it was noted that there is no universally accepted definition for customer relationship management and CRM has been defined in prominent 
previous research according to different aspects illustrate the evolution in the way CRM has been viewed, on the other hand, CRM is perceived differently among companies and experts [9, 18 and 21]. For example, Chang et al [16] viewed CRM as an important business approach to build long term, profitable relationships with specific customers, while Khodakarami and Chan [22] defined customer relationship management a set of methodologies and organizational processes to attract and retain customers through their increased satisfaction and loyalty.

In this line, Martín et al. [23] pointed out that when we talk about customer relationship management, we specifically refer to the business strategy that involves a systematic process to manage, initial, maintenance, and ending relationship with the customer through all windows of contact in order to maximize the value of the relationship. According to Kotler and Keller [24] customer relationship management is the process of carefully managing detailed information about individual customers and all customers "touch points" to maximize loyalty and a customer touch point is any occasion on which a customer encounters the brand and product from actual experience to personal or mass communications to causal observation.

It is worth mentioning that heavy emphasis was put on the role of information technology when defining customer relationship management. For instance, Wei et al. [25] described customer relationship management as the adoption of information technology to develop new customers and retain old customers as to keep long-term and closed relationship, which aims to improve customer relationship and thus can help increase customer loyalty, customer retention and customer profitability. Similarly, Khodakarami and Chan [22] viewed CRM as a group of information systems that enable organizations to contact customers and collect, store and analyze customer data to provide a comprehensive view of their customers.

Consistent with the above, other such as Santouridis and Tsachtani, [20] and Shim et al. [26] shed light on information technology in CRM practices, they indicated that customer relationship management relies heavily on gathering and processing customer data in order to extract information that will help to identify ideal customers and customize their offerings $s$ a result of this, information technology plays a pivotal role as an enabler of successful CRM implementation. In this study, we adopted the operational concept that define customer relationship management as a business approach involves a set of methodologies and information and organizational processes to build long term and profitable relationships with customers for creating competitive advantage and achieving marketing innovation capability.

Based on the previously mentioned concepts and definitions implementing the new dimensions of CRM involves main activities such as, developing customers profile, segmenting markets, anticipating customers' needs, customizing service offers, identifying appropriate channels to reach customers, identify and focusing on profitable customers and assessing customers' retention behavior [e.g. 22].

In literature, customer relationship management readiness means that organizations collaborate to CRM infrastructure, software, departments and employees in order to implement CRM relational information processes effectively. Therefore, customer relationship management readiness consists of two dimensions, (a) organizational readiness which refers to the capability of organizations to adopt information technology systems, and (b) technology readiness which includes hardware, software and computer networks that facilitate CRM processes and information exchange [16]. Given that the readiness concept becomes more complicated when an organization, rather than individuals, is the focus of adoption because readiness tends to depend on a wide variety of factors [27].

Recently literature has begun to link the practice of customer relationship management with marketing innovation capabilities. For example, Koziol et al. [28] reported that customer relationship management considered one of the determinants of an organization's innovation potential in the context of marketing. While others [e.g. 2, 29 and 30] concluded that using CRM in creating and maintaining relationships with customers and keeping long-term partnerships is an imperative strategy to improve a firm's innovation capability and enhance competitive advantage. Given that managing innovation processes in company is a real problem, which are managers of the company faced [31].

According to Gupta and Malhotra [32] marketing innovation can be understood as the application of new ideas, concepts, communications and theories in marketing practices by businesses to sustain 
their market position. Similarly, Gottlichova and Soukalova [11] perceived marketing innovation as introducing new methods supporting marketing activities to achieve competitive advantage. To understand the concept of innovation marketing capability more precisely, it is necessary to identify another related concept. Innovation capability, which refers to the implementation or creation to technologies as applied to systems, activities, policies, programs, products, process, communications, devices or services that are new to an organization [12]. For the current study purpose, we adopted the operational concept that defines the marketing innovation capability as the organization's ability to implement new ideas, concepts, methods and approaches in marketing activities, practices and communication to gain and maintain competitive advantage and maximizing revenue.

Drawing upon the comprehensive review of the specialized literature and based on the theoretical background discussed earlier as well as the data collected from a series of qualitative studies in the preliminary stage of our current study the following hypotheses that guide the investigation were formulated for testing their relationships:

$H_{1}$ : Implementing the new dimensions of CRM has significant positive impact on marketing innovation capability:

$H_{1 a}$ : Developing customers profile positively influences marketing innovation capability

$H_{l b}$ : Segmenting markets positively influences marketing innovation capability

$H_{I c}$ : Anticipating customers' needs positively marketing innovation capability

$H_{l d}$ : Customizing offers positively influences marketing innovation capability

$H_{l e}$ : Identifying appropriate channels to reach customers positively influences marketing innovation capability

$H_{l f}:$ Identify and focusing on profitable customers positively influences marketing innovation capability

$H_{l g}$ : Assessing customers' retention behavior positively influences marketing innovation capability

$\mathrm{H}_{2}$ : CRM readiness significantly mediates the relationship between CRM implementation and marketing innovation capability:

$H_{2 a}$ : The positive effect of CRM implementation on marketing innovation capability is greater for construction companies with higher CRM organizational readiness.

$H_{2 b}$ : The positive effect of CRM implementation on marketing innovation capability is greater for construction companies with higher CRM technical readiness.

$H_{3}$ : Construction companies tend to implement the full features of the new dimensions of customer relationship management

\section{Constructing the Structural ANALYTiC Model}

In this paper, a structural research model was developed through the integration of the constructs mentioned in the previous hypotheses, which incorporated many of the relevant features of the new proposed approach of CRM identified in literature to be examined simultaneously in one framework for validation. The strength of the hypothesized relationships embedded in the model and its robustness of predicting marketing innovation capability were evaluated. Therefore our research model contained 10 constructs, 7 independent variables (developing customers profile, segmenting markets, anticipating customers' needs, customizing construction company offers, identifying appropriate channels to reach customers, identify and focusing on profitable customers and assessing customers' retention behavior) and 2 mediating variables (CRM organizational and technical readiness) as predictors of the criterion dependent variable marketing innovation capability. In addition to one variable used to assess the actual implementation of the new dimensions of CRM in Egyptian construction companies.

Structural equation modeling (SEM) was adopted in our data analysis to provide efficient estimation for separate multiple regression equations estimated simultaneously where constructs could be represented by a summed scale and assess the relative importance of each construct. Thus, the initial prediction multiple regression equation $(E G 1)$ of the research model can be presented as follows: 
A Multidimensional CRM Approach for Enhancing Marketing Innovation Capabilities of Construction Companies Using Structural Equation Modeling

$Y_{I M I C}=a+b_{D C P} D C P+b_{S M K} S M K-b_{A C N} A C N+b_{C C O} C C O+b_{C H N} C H N+b_{P R C} P R C+b_{O R G} O R G+b_{T C H}$ $T C H$--------(EGl)

Where:

DCP=Developing customers profile

SMK=Segmenting markets

ACN=Anticipating customers' needs

$\mathrm{CCO}=$ Customizing construction company offers

CHN=Identifying appropriate channels to reach customers

$P R C=I d e n t i f y$ and focusing on profitable customers

$A C R=$ Assessing customers' retention behavior

ORG $=$ CRM Organizational readiness

TCH=CRM technical readiness

$Y_{M I C}=$ Marketing Innovation Capability

Overall, the evidence of a good model fit, reliability, and convergent validity indicated that the measurement model war appropriate for testing the structural research model. However, the measurement items used to operationalize these constructs were derived from previous relevant works [e.g. 11,12 and 32] for measuring marketing innovation capabilities, Chang et al. [14] for measuring the implementation of new CRM activities, Moreno et al [2] for measuring CRM technical and organizational readiness. In addition, the wording of the items was adjusted to match the present context.

\section{RESEARCH METHODOLOGY}

A richer research methodology is used in this empirical study combining quantitative and qualitative methods to validate the research model and empirically test the hypothesized relationships among its variables. Thus, the research process involved multi-stage procedures as follow.

\subsection{Preliminary Qualitative Study}

Preliminary qualitative study data were collected by means of focus group, complemented by a series of in-depth face-to-face interviews with 10 senior construction company managers who had positions of responsibility in customer relationships management implementation, to gain deeper understanding of the phenomenon under consideration, supports hypotheses development and establishes the criteria and relationship constructs relevant to our empirical study. Issues arising from this stage were used as a basis for the subsequent quantitative study.

\subsection{Quantitative Research Design}

Furthermore, a quantitative research study in the form of questionnaires was conducted in two stages, first the pilot survey was administrated during July 2016 to test the questionnaire's reliability, and second a cross-sectional national sample survey for data collection was conducted during September to November 2016. The target population was full-time CRM employees of construction companies operating in the two major business cities in Egypt (Cairo and Alexandria) using simple random sampling technique to gain as many representative samples as possible and increase generalizations of the results. The list of construction companies in Egypt (at http://www.egypt-business.com/Company/ katalog/Construction) served as a sampling frame for this study. Among a total of 500 questionnaires that were randomly distributed, 186 valid responses were obtained and used in data analysis, after removing invalid answers, yielding a usable response rate of 37.20 percent for the overall survey. The respondents did not need assistance in completing the questionnaires as the information on the cover letter and instructions on how to fill the questionnaire were explicit.

\subsection{Instrument, Validity and Reliability}

Before the full-scale survey, the present study took steps to ensure reliability and validity. The scales used for measurement process were adapted from well-established survey items of previous works and modified to suit the purpose of the current study. Research variables were measured by multiple 
items, using a 7-point multi-item Likert scale ranging from 1-7. All items included in the questionnaire were cross-validated before they were added. The questionnaire was pre-tested and then followed by a pilot test to validate the instrument. In the pre-test, the respondents were asked to comment on listed items regarding the research constructs, including instrument length, questions format, the wording of scales, and other comments on how the questionnaire could be improved.

The pilot test aimed to ensure that questionnaire adequately addressed the relevant issues and reducing possible ambiguity in the questions. Based on pre-test and pilot test feedback, modifications had been made to improve readability and appropriateness. The revised questionnaire was again pretested and the final version was found worked well and the instrument has confirmed content validity. The Cronbach's alpha coefficient test was used to evaluate the internal consistency reliability. The reliability analysis results exhibited an acceptable level, the value of Cronbach's alpha of every construct is greater than 0.8 (ranging from 0.81 to 0.94 ). Also, exploratory factor analysis was used to evaluate the construct validity and the results demonstrate acceptable standard.

\section{Data Analysis, Model Testing and Results}

The empirical data collected by the survey was analyzed and tested using statistical software packages (SPSS). The analysis included descriptive statistics, correlation to examine the relationships among variables, multiple regression analyses with its associated statistical inference tests were applied due to the presence of many predictors in the study, to test for the joint and independent influence of predictors on the criterion variable. Stepwise forward inclusion techniques of regression analysis were performed to assess the relative importance of predictor variables mentioned earlier and to select a smaller subset of variables that account for most of the variation in the criterion variable. To determine whether any multicollinearity effects among the independent variables included in the model equations, the total correlation matrix was reviewed in-depth and the results revealed that there was no severe multicollinearity problem among the regressors, which suggested that predictors were tolerated in the criterion variable. The results of testing each of the hypotheses are given below.

\subsection{The Results of Testing Hypotheses $\mathrm{H}_{1}$ and $\mathrm{H}_{2}$}

The summary output of the stepwise regression analysis (forward inclusion) introduced in table 1 led to accept the following hypotheses $\mathrm{H}_{1 \mathrm{a}}, \mathrm{H}_{1 \mathrm{~b}}, \mathrm{H}_{1 \mathrm{f}}$, and $\mathrm{H}_{2 \mathrm{a}}$, while the statistical significance test supported this acceptance and confirmed the hypothesized relationships.

A strong significant and meaningful correlation is found between criterion variable $\mathrm{Y}_{\text {MIC }}$ and the above mentioned predictor variables (Multiple $R$ "model $4 "=0.881$ ). The value of F- ratio "model 9 " $(F(4,181)=156.880$ at $p<0.000000000)$ is statistically significant indicating that the results of the model could hardly have occurred by chance. Thus, the goodness-of-fit of the model considered satisfactory. The coefficient of determination, multiple R-square suggested that the proposed model is valid, the predictor variables of the model explained the major proportion $(77.60 \%)$ of the variability observed among the criterion variable $\mathrm{Y}_{\mathrm{MIC}}\left(R^{2}\right.$ "model $\left.4 "=0.776\right)$, which reinforce our confidence in the hypotheses testing results and provides support for the above mentioned association.

Table1. Summary output of the stepwise regression analyses (forward inclusion)

\begin{tabular}{|l|l|l|l|l|l|l|l|l|l|}
\hline Model & $\mathrm{R}$ & $\mathrm{R}^{2}$ & Adj. $\mathrm{R}^{2}$ & $\mathrm{SS}_{\text {reg }}$ & $\mathrm{SS}_{\text {res }}$ & $\mathrm{SS}_{\text {total }}$ & df & $\mathrm{f}$ & Sig. \\
\hline 1 & $0.862^{\mathrm{a}}$ & 0.743 & 0.742 & 337.950 & 116.873 & 454.823 & 1,184 & 532.057 & $0.0000000^{*}$ \\
\hline 2 & $0.871^{\mathrm{b}}$ & 0.759 & 0.756 & 345.231 & 109.591 & 454.823 & 2,183 & 288.240 & $0.0000000^{*}$ \\
\hline 3 & $0.877^{\mathrm{c}}$ & 0.770 & 0.766 & 350.214 & 104.608 & 454.823 & 3,182 & 203.103 & $0.0000000^{*}$ \\
\hline 4 & $0.881^{\mathrm{d}}$ & 0.776 & 0.771 & 350.003 & 101.819 & 454.823 & 4,181 & 156.880 & $0.0000000^{*}$ \\
\hline a. & Model (1): Predictor variables entered: (constant), DCP \\
b. Model (2): Predictor variables entered: (constant), DCP, PRC \\
c. Model (3): Predictor variables entered: (constant), DCP, PRC, ORG \\
d. Model (4): Predictor variables entered: (constant), DCP, PRC, ORG, SMK \\
Criterion Variable: $Y_{\text {MIC }}$ \\
\hline
\end{tabular}

$*_{p}<0.00000000$ levels of significant

Furthermore, the adjusted $R^{2}$ of the model 4, which is a more conservative estimate of variance by considering error variance, is 0.771 . This reinforces our confidence that the overall explanatory power of the research model considered high and quite capable of explaining the observed variance among the sample. As seen from table 1 among 9 predictor variables only 4 variables or dimensions 
A Multidimensional CRM Approach for Enhancing Marketing Innovation Capabilities of Construction Companies Using Structural Equation Modeling

(developing customers profile, identifying and focusing on profitable customer, CRM organizational readiness and segmenting marketing) were found to have a critical significant impact on the criterion variable $\mathrm{Y}_{\mathrm{MIC}}$, they succeeded in entering into model 4 equation. The stepwise technique determined which of the initial 9 constructs should be included as predictors in the final equation.

Nevertheless, tracing the order in which these variables have been entered the equation suggested that developing customers profile $(D C P)$ specifically have the most significant impact on construction companies' marketing innovation capability as it alone explained 74.30 percent of such total variation $\left(R^{2}\right.$ "model $\left.1 "=0.743\right)$. For easily comparing and assessing the relative impact of each predictor variable on the criterion variable, standardized beta coefficients $(\boldsymbol{\beta})$ and t-test values of the 4 variables that succeeded in entering into model 4 were presented in table 2.

Table2. Standardized and non-standardized coefficients of variables included in the stepwise regression

\begin{tabular}{|l|l|l|l|l|l|l|}
\hline Predictors & \multicolumn{2}{|l|}{$\begin{array}{l}\text { Non-standardized Regression } \\
\text { Coefficients }\end{array}$} & \multicolumn{2}{l|}{ Standardized Beta Coefficients } & \multicolumn{2}{l|}{$t$-test } \\
\hline $\begin{array}{l}\text { "Model } \\
4 "\end{array}$ & Symbol & Value & Symbol & Value & Value & Sig. \\
\hline$D C P$ & $b_{D C P}$ & 0.729 & $\boldsymbol{\beta}_{D C P}$ & 0.723 & 13.998 & $0.000000^{*}$ \\
\hline$P R C$ & $b_{P R C}$ & 0.188 & $\boldsymbol{\beta}_{P R C}$ & 0.133 & 3.619 & $0.000000^{*}$ \\
\hline$O R G$ & $b_{O R G}$ & 1.879 & $\boldsymbol{\beta}_{O R G}$ & 1.437 & 2.876 & $0.01000^{* *}$ \\
\hline$S M K$ & $b_{S M K}$ & 1.681 & $\boldsymbol{\beta}_{S M K}$ & 1.294 & 2.727 & $0.01000^{* *}$ \\
\hline Intercept & $\mathrm{a}$ & 0.484 & & & & \\
\hline
\end{tabular}

${ }^{*} p<0.00000000$ levels of significant

$* * p<0.01000000$ levels of significant

The finding shown in table 2 is consistent with the results summarized in table 1, the first proposed dimension of CRM developing customers profile had the highest effect on construction company's marketing innovation capability $\mathrm{Y}_{\mathrm{MIC}}$ with positive association (highest Beta value: $\beta_{D C P}=0.723$ and highest $t$-test value: $t=13.998, p<0.000000)$ followed by identifying and focusing on profitable customers $\left(\beta_{P R C}=-1.33, t=3.619, p<00.000000\right)$. On the other hand, rest 5 dimensions of CRM implementation failed to enter the regression equation "model 4" denoting that they have less significant impact on construction company's marketing innovation capability in the Egyptian market. The values of the non-standardized regression coefficients in table 2 were utilized for mathematically predicting the construction company's future marketing innovation capability by the following final research equation (EQ2):

$Y_{M I C}=0.484+0.729 D C P+0.188 P C R+1.879 O R G+1.681 S M K---\cdot--\cdot-----(E G 2)$

Finally, table 3 provide a brief summary of hypotheses testing and their structural paths.

Table3. Structural Model Result

\begin{tabular}{|l|l|l|l|}
\hline Hypotheses & Structural Paths & Standardized Beta Coefficients & Results \\
\hline$H_{l a}$ & CRM "DPC" $\longrightarrow Y_{M I C}$ & $0.723^{*}$ & Supported \\
\hline$H_{l b}$ & CRM "SMK" $\longrightarrow Y_{M I C}$ & $1.294^{* *}$ & Supported \\
\hline$H_{l c}$ & CRM "ACN" $\longrightarrow Y_{M I C}$ & Excluded & Not supported \\
\hline$H_{l d}$ & CRM "CCO" $\longrightarrow Y_{M I C}$ & Excluded & Not supported \\
\hline$H_{l e}$ & CRM "CHN" $\longrightarrow Y_{M I C}$ & Excluded & Not supported \\
\hline$H_{l f}$ & CRM "PRC" $\longrightarrow Y_{M I C}$ & $0.133^{*}$ & Supported \\
\hline$H_{l g}$ & CRM "ACR " $\longrightarrow Y_{M I C}$ & Excluded & Not supported \\
\hline$H_{2 a}$ & CRM $\longrightarrow$ ORG $\longrightarrow Y_{M I C}$ & $2.876^{* *}$ & Supported \\
\hline$H_{2 b}$ & CRM $\longrightarrow$ TCH $\longrightarrow Y_{M I C}$ & Excluded & Not supported \\
\hline
\end{tabular}

${ }^{*} p<0.00000000$ levels of significant

$* * p<0.01000000$ levels of significant

\subsection{The Results of Testing Hypothesis $\mathrm{H}_{3}$}

The results of descriptive analysis in table 4 did not support the acceptance of hypothesis $\mathrm{H}_{3}(\overline{\mathrm{x}}=$ 1.76881720$, SD $=0.59301857$, and Skewness $=0.115803805106958)$. Despite all Construction 
companies operating in Egypt reported that they already implement customer relationship marketing, the findings showed that Egyptian construction companies, included in our study, are most likely practice partially the new dimensions of CRM (59.70\%). While the remaining percent either implement these dimensions in a limited manner (31.70\%), or fully implemented $(8.60 \%)$.

Table4. Descriptive Statistics of CRM implementation of construction companies operating in Egypt

\begin{tabular}{|l|c|l|l|c|}
\hline $\begin{array}{c}\text { CRM } \\
\text { Implementation }\end{array}$ & Percent & Mean $\overline{\mathrm{x}}$ & Standard Deviation SD & Skewness \\
\hline Full & $8.60 \%$ & & & \\
\hline Partial & $59.70 \%$ & 1.76881720 & 0.59301857 & 0.115803805106958 \\
\hline Limited & $31.70 \%$ & & & \\
\hline
\end{tabular}

The graphical presentation in Figure 1 clearly illustrated the findings discussed above; the values of the spider diagram strongly tend toward the right side reflecting the partial CRM implementation among Egyptian Construction companies. A P-P plot of regression standardized residual for assessing the assumption of normality was conducted, to see if the error term $\epsilon$ is actually normally distributed. The plot, in figure 2, showed that the data met the assumptions of normality, quantile pairs fell nearly on a straight line and quite close to the 45-degree line. Thus, it can be concluded that the data used in this research are approximately normally distributed and the fitted model is appropriate.

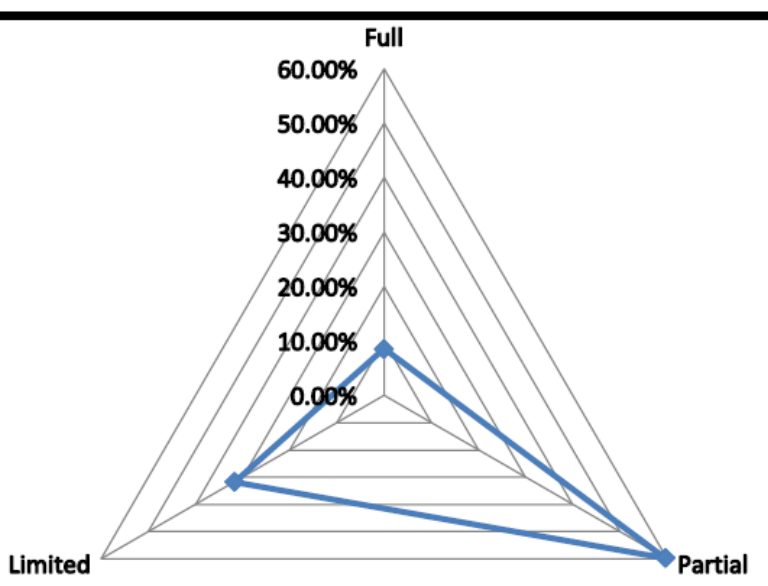

Figure1. Spider Diagram of CRM actual implementation in Construction companies

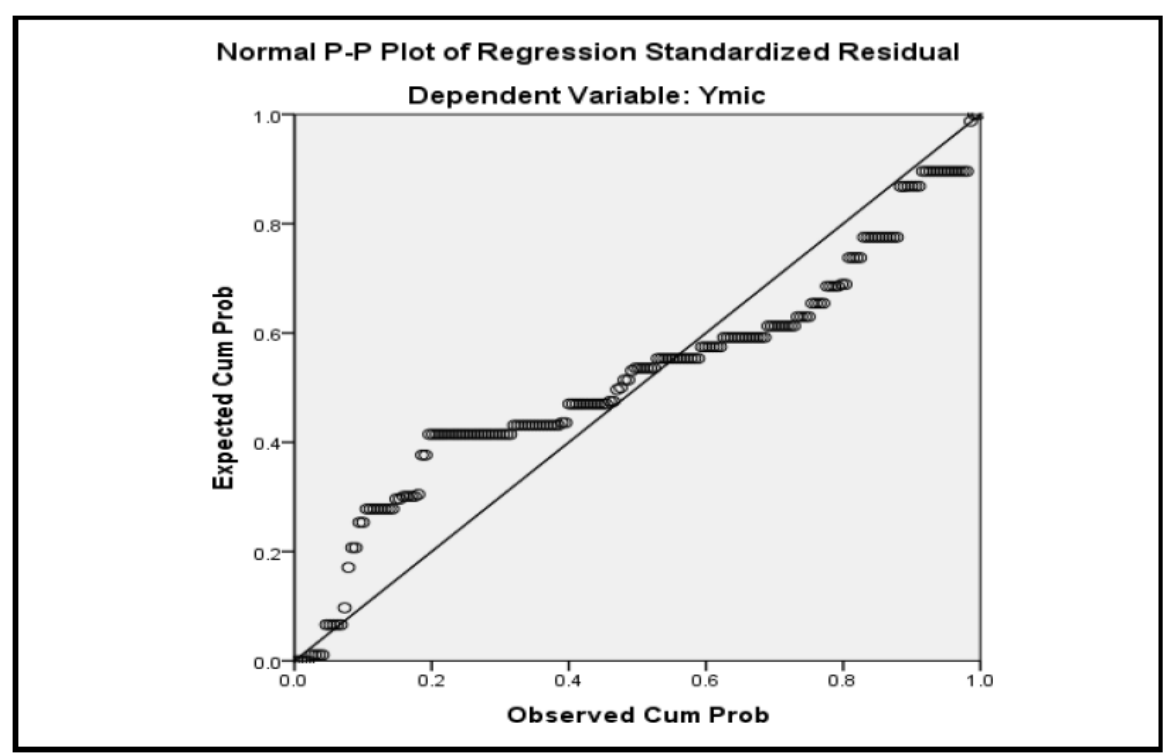

Figure2. Normal P-P plot of regression standardized residual 


\section{CONCLUSION AND IMPLICATIONS}

This paper has taken a further significant step in contributing to both theory and practice of e-training, and to help address some gaps in the current body of literature. More specifically, this study has made a number of important practical (managerial) implementations and theoretical (academic) contributions. In term of practical implications, the results confirmed the importance of applying the new multidimensional approach of customer relationship management in construction companies. The results showed that CRM implementation has a significant impact on construction company's marketing innovation capability, thus, to attain the desired marketing innovation capability, companies must look beyond the traditional approach of CRM. Mangers should continually strengthen the completeness of proposed multidimensional approach of CRM for establishing lifetime value based on sustainable relationship and in turn enhance construction company competitive capabilities and marketing innovation capability. Continuing with the previous point, our findings can help practitioners to develop more customized customer relationship practices as well as considering the barriers of both organizational and technical CRM readiness.

Applying the proposed approach of CRM enables construction companies to easily segment their customers efficiently, and in turn, marketing segmentation can identify profitable and unprofitable customers. Nevertheless, the results suggest that to implement the new multidimensional approach of customer relationship management successfully companies must pay more attention to CRM organizational readiness which will make a determinant impact on their marketing innovation capabilities. Finally, the current study found that the first feature of CRM, developing customers profile had the highest impact on company's marketing innovation capability; therefore, this dimension especially should be taken in considering when formulating CRM strategies, particularly there are different perceptions of relationship marketing management [33].

From an academic and research standpoint, this study provides a novel multidimensional approach for implementing CRM, as well as empirical evidences and validation for the existing specialized literature concerning customer relationship management and added empirical weight to research addressing construction companies. The findings of the empirical study provide support for the research model and for the hypotheses regarding the directional linkage among its variables. The high overall explanatory power of our model indicated that this model is capable of explaining high proportion of the variance observed in Construction companies' marketing innovation capability. Furthermore, this research attempted to integrate and encompass the most frequently cited constructs in the literature, and applied them in the local context in order to best examine the phenomenon, which have never been integrated before into one framework subject, to examination for validation and relationship. Therefore, the proposed model contained variables that have not been tested simultaneously in previous works.

\section{LIMITATIONS AND FURTHER RESEARCH}

To make the research findings more objective, few limitations that present opportunities for future research should be discussed. First, the research model was validated using empirical data gathered from Egypt and therefore the findings may be affected by the culture in this developing country. Since the study is cross-sectional in design, a further examination of our argument using a longitudinal study is recommended in the future to investigate our model in different time periods.

Apart from the above, we must point out that although the majority of the hypothesized relationships were validated, and significant, and our structural model yielded a relatively high level value of multiple correlation coefficient, the obtained value of multiple $\mathrm{R}$-square $\left(R^{2}\right)$, implies that other additional variables, which may not be considered in our research model, can be addressed to enhance the model ability for prediction.

However, there are other opportunities to build on this study in future research. Suggested areas include re-examining the proposed model in other countries with different cultures or other industry in the same country, and make comparisons, to see how the findings would be affected. It would be valuable that future research use other theoretical bases or different methodologies and sample to derive different predictions. In addition, future research can analyze the relative advantage of those construction companies, which implement the new approach of CRM opposed to other business companies to see the differences. 


\section{ACKNOWLEDGEMENTS}

The author would like to express thanks for chief executive officers and general managers of Egyptian construction companies for helping data collection without which this empirical study would not have been possible. The author is also very grateful for the insightful feedback and valuable comments on earlier draft during development of this paper.

\section{REFERENCES}

[1] Payne, A. and Frow, P. (2017) Relationship marketing: looking backwards towards the future, Journal of Services Marketing, 31/1, pp 11-15

[2] Moreno, A., Lockett, N. and Morales, V. (2015). Exploring the role of knowledge management practices in fostering customer relationship management as a catalyst of marketing innovation, Baltic Journal of Management, 10 (4), 393-412

[3] Sarmaniotis, C., Assimakopoulos, C. and Papaioannou, E. (2013). Successful implementation of CRM in luxury hotels: determinants and measurements, Euro Med Journal of Business, 8 (2), 134- 153

[4] Valmohammadi, C. and Beladpas, M. (2014). Customer relationship management and service quality, a survey within the banking sector, Industrial and Commercial Training, 46 (2), 77-83

[5] Jamali, R., Moshabaki, A., Aramoon, H. and Alimohammadi, A. (2013). Customer relationship management in electronic environment, The Electronic Library, 31 (1), 119-130

[6] Sangle, P. and Awasthi, P. (2011). Consumer's expectations from mobile CRM services: a banking context, Business Process Management Journal, 17 (6), 898-918

[7] Li, L. and Mao, J. (2012). The effect of CRM use on internal sales management control: An alternative mechanism to realize CRM benefits, Information \& Management, 49, 269-277.

[8] Stein, A., Smith, M. and Lancioni, R. (2013). The development and diffusion of customer relationship management (CRM) intelligence in business-to-business environments, Industrial Marketing Management, 42, 855-861

[9] Josiassen, A., Assaf, A. and Cvelbar, L. (2014). CRM and the bottom line: Do all CRM dimensions affect firm performance?, International Journal of Hospitality Management, 36, 130 136

[10] Moreno, A., Lockett, N. and Morales, V. (2014). Paving the way for CRM success: The mediating role of knowledge management and organizational commitment, Information \& Management, 51, 1031-1042

[11] Göttlichová, M. and Soukalová, R. (2015). Options for innovation of marketing approaches to the market in the non-profit sector, Procedia -Social and Behavioral Sciences, 175, 334-341.

[12] Lin, R., Chen, R. and Chiu, K. (2010). Customer relationship management and innovation capability: an empirical study, Industrial Management \& Data Systems, 110 (1), 111-133

[13] Tzokas, N., Kim, Y., Akbar, H. and Al-Dajani, H. (2015). Absorptive capacity and performance: The role of customer relationship and technological capabilities in high-tech SMEs, Industrial Marketing Management 47, 134-142

[14] Nyadzayo, M. and Khajehzadeh, S. (2016). The antecedents of customer loyalty: A moderated mediation model of customer relationship management quality and brand image, Journal of Retailing and Consumer Services, 30, pp 262-270

[15] Mekkamol, P., Piewdang, S. and Untachai, S. (2013). Modeling e-CRM for Community Tourism in Upper Northeastern Thailand, Procedia- Social and Behavioral Sciences, 88, 108-117

[16] Chang, H., Wong, K. and Fang, P. (2014). The effects of customer relationship management relational information processes on customer-based performance, Decision Support Systems 66, $146-159$

[17] Sheth, J. (2017). Revitalizing relationship marketing, Journal of Services Marketing, 31/1, pp 610

[18] Sivaraks,P., Krairit, D. and Tang, J. (2011). Effects of e-CRM on customer-bank relationship quality and outcomes: The case of Thailand, Journal of High Technology Management Research, $22,141-157$

[19] Kubina, M. and Lendel, V. (2015). Successful Application of Social CRM in The Company, Procedia Economics and Finance 23, 119-1194 
[20] Santouridis, I. and Tsachtani, E. (2015). Investigating the Impact of CRM Resources on CRM Processes: a Customer Life Cycle Based Approach in the Case of a Greek Bank, Procedia Economics and Finance, 19, $304-313$

[21] Trizonova, M., Matova, H., Dvoracek, J. and Sadek, S. (2015). Customer Relationship Management based on Employees and Corporate Culture, Procedia Economics and Finance, 26, 953-959

[22] Khodakarami, F. and Chan, Y. (2014). Exploring the role of customer relationship management (CRM) systems in customer knowledge creation, Information \& Management, 51, 27-42

[23] Martín, S., Jiménez, N. and Catalán, B. (2015). The firms benefits of mobile CRM from the relationship, Revista Española de Investigación de Marketing ESIC, Article in Press

[24] Kotler, P. and Keller, K. (2012). Marketing Management, Global Edition, Pearson Education limited

[25] Wei, J., Lee, M., Chen, H. and Wu, H. (2013). Customer relationship management in the hairdressing industry: An application of data mining techniques, Expert Systems with Applications 40, 7513-7518

[26] Shim, B. Choi, K. and Such, Y. (2012). CRM strategies for a small-sized online shopping mall based on association rules and sequential patterns, Expert Systems with Applications, 39, 77367742

[27] Yen, H., Wang, W., Wei, C., Hsu, S. and Chiu, H. (2012). Service innovation readiness: Dimensions and performance outcome, Decision Support Systems, 53,813-824

[28] Koziol, L., Koziol, W., Wojtowicz, A. and Pyrek, R. (2014). Relationship marketing: a tool for supporting the company's innovation process, Procedia Social and Behavioral Sciences, 148 (1), $86-866$

[29] Chang, W., Park, J. and Chaiy, S. (2010). How does CRM technology transform into organizational performance? A Mediating role of marketing capability, Journal of Business Research, 36, 849-855

[30] Mu, J. (2015). Marketing capability, organizational adaptation and new product, Industrial Marketing Management, 49, 151-166

[31] Lendel, V., Hittmár, S. and Siantová, E. (2015). Management of Innovation Processes in Company, Procedia Economics and Finance, 23, 86-866

[32] Gupta, S. and Malthora, N. (2013). Marketing innovation: a resource-based view of international and local firms, Marketing Intelligence \& Planning, 31 (2), 111-126

[33] Gummesson, E. (2017). From relationship marketing to total relationship marketing and beyond, Journal of Services Marketing, 31/1, pp 16-19 